Leading Article

\title{
Irreversible renal failure in men with outflow obstruction: is it a preventable disease?
}

\author{
David E. Neal \\ Freeman Hospital, Newcastle upon Tyne NE7 7DN, UK
}

\section{Introduction}

By the age of 60 years, more than a half of men have histological evidence of benign prostatic hyperplasia, ${ }^{1}$ although not all have symptoms. No amount of exercise delays its development, no diet causes its regression; the only effective change in lifestyle is castration before puberty: not an appealing choice. In the early decades of this century, prostatectomy carried an operative mortality of $20 \%$ in most hospitals. ${ }^{2}$ Nowadays, transurethral prostatectomy (TURP) must be one of the safest of major operations, the in-patient mortality being less than $0.2 \% .^{3}$ However, recent studies have shown an increased long term risk of death after TURP compared with open operation ${ }^{4}$ and an unsatisfactory outcome in about a fifth of men. ${ }^{5-9}$ These studies have occasioned further discussion. ${ }^{10,11}$

Sadly, renal failure remains the cause of first referral for some men, ${ }^{12}$ rather than the earlier symptoms of obstruction - often long-neglected and attributed to ageing. Surely, it should be possible to identify men whose bladder is not emptying because of prostatic obstruction before their kidneys fail?

\section{Scope of problem}

About a tenth to a fifth of men in their forties will subsequently undergo prostatectomy. ${ }^{13,14}$ However, many with symptoms do not consult their doctor. A recent study of men with no urological history, showed that a fifth of elderly men had symptoms of a similar severity to men undergoing prostatectomy. ${ }^{15}$ Of the 19 men who presented with severe renal failure owing to obstruction studied by Sacks, ${ }^{12}$ most had not seen a urologist previously. Many men are not asymptomatic but merely uncomplaining.

Correspondence: D.E. Neal, M.S., F.R.C.S., B.Sc. Received: 9 April 1990
Renal impairment and upper tract dilatation in outflow obstruction is caused by obstruction at the vesico-ureteric junction which in turn is the result of impaired bladder emptying plus abnormal detrusor pressure activity. The other cause, not considered further here, is prostate cancer which can infiltrate locally producing ureteric obstruction. In men undergoing prostatectomy the incidence of upper tract dilatation is between $5 \%-10 \%{ }^{16,17}$ However, there is a close relationship between impaired bladder emptying and upper tract dilatation. About $10 \%-15 \%$ of men undergoing prostatectomy have a palpable painless bladder, but a further $15 \%$ have a residual urine of $100 \mathrm{ml}-300 \mathrm{ml} .{ }^{17}$ These men are at increased risk of upper tract damage ${ }^{18-20}$ and might present later with renal failure if their outflow obstruction were to be left untreated.

\section{Chronic retention of urine}

Chronic retention of urine is commonly taken to be a painless palpable bladder which corresponds to a residual volume of urine of about $300 \mathrm{ml}$. The reason why some men with obstruction develop impaired bladder emptying is not well understood. The risk of the individual with minimal symptoms developing retention and renal impairment is low. ${ }^{21}$ In one study, 107 men (mean age 61 years) with symptoms had undergone urodynamic studies and for various, unstated reasons had not undergone prostatectomy. Over the ensuing 5 years, 19 had worsening symptoms and 10 required operation; the remainder were no worse. However, it is unclear whether these men were representative, for they were younger and their mean flow rate $(13 \mathrm{ml} / \mathrm{s})$ was greater than men undergoing prostatectomy at the same time in Bristol $(8 \mathrm{ml} / \mathrm{s}) .{ }^{22}$ Moreover, the 10 conservatively treated men who subsequently underwent operation had low flow rates $(8 \mathrm{ml} / \mathrm{s})$. This study suggests that selected younger men with minimally decreased flow rates have a low rate of progression at 5 years. 


\section{High pressure chronic retention}

Mitchell pointed out that men with a hard bladder on palpation were more likely to have renal impairment than men with a soft bladder. Urodynamic studies have confirmed this suggestion culminating in the idea that there was a special group of men who presented with urgency, incontinence, enuresis, hypertension and renal failure. ${ }^{19}$ Urodynamic studies demonstrated that bladder pressure was raised throughout filling and that there was a high tonic rise in pressure. It was suggested that these men had a specific condition defined as high pressure chronic retention.

More recent studies have shown marked discrepancies between conventional urodynamic studies and long-term natural filling ambulatory studies. ${ }^{23}$ The high pressure rises seen during conventional urodynamic studies do not occur during ambulatory monitoring studies and, instead, frequent phasic activity is found. Similar features have been found in patients with neuropathic bladder dysfunction at risk of renal damage. ${ }^{24}$ In this regard, it is noteworthy that severe outflow obstruction is associated with damage to the innervation of the detrusor muscle. ${ }^{25}$

The concept of high pressure chronic retention was useful because it pointed out that not all men with impaired bladder emptying were at risk of renal failure. However, the specificity implied by the name was misleading, for it now seems that these men with chronic retention merely form one end of a spectrum of abnormality. 17,20,23,26

\section{Renal failure in men with outflow obstruction}

About a half of men with palpable painless bladders (chronic retention) have upper tract dilatation or an increased serum creatinine. ${ }^{20,23}$ Identification of men with renal impairment is important, for they may require a period of catheter drainage before prostatectomy to allow renal function to improve. Prostatectomy in men with impaired renal function carries an increased risk. ${ }^{27}$ These men are more likely to have urinary sepsis and their capacity to respond to the cardiovascular changes which may result from hypovolaemia, hypoxia and sepsis is markedly reduced.

However, identification of upper tract damage by biochemical testing remains problematic. In a recent study in Newcastle, 15 of 31 men with chronic retention were found to have upper tract dilatation on ultrasound scanning. Two of them had ${ }^{51} \mathrm{Cr}$ EDTA clearances of $>60 \mathrm{ml} / \mathrm{min}$ and 9 of the $15 \mathrm{had}$ a serum creatinine of $<200 \mu \mathrm{mol} / \mathrm{l}$. In other words, measurement of serum creatinine alone would have missed $60 \%$ of men with upper tract dilatation.

\section{Management of chronic retention}

Men with significant renal impairment should be treated by a period of catheter drainage. This must be continued until renal function is stable, which may rarely take 3-4 weeks. ${ }^{28}$ It is well known that catheter drainage may be followed by a diuresis, which in the early days may merely reflect appropriate excretion of retained fluid and sodium. However, profound fluid losses may continue as a consequence of damaged tubular function. The replacement of these fluid losses in elderly men with poor cardiovascular reserves can pose major problems and requires careful management.

The early results of prostatectomy in these men are good. In most men, upper tract dilatation resolves, bladder emptying improves, and bladder pressures decrease.$^{20}$ However, some have found that upper tract dilatation persists, ${ }^{29}$ and most agree that about $30 \%$ of men remain with significant impairment of bladder emptying: these men may be at risk of permanent renal impairment in the future. ${ }^{12}$ Bladder emptying must be assessed by ultrasound measurement at the post-operative outpatient visit. The patient with severe impairment of bladder emptying or renal function should not be discharged from follow-up ${ }^{12}$ (see below). In some men urodynamic studies may be necessary. In a recent study in Newcastle, one man remained obstructed with upper tract dilatation after prostatectomy - this resolved after a further operation. In some men with persistently poor bladder emptying owing to detrusor failure, it may be necessary to teach the patient to perform intermittent clean self-catheterization - a procedure which is safe and which should prevent further renal deterioration. ${ }^{30}$

\section{Persistent renal failure}

Unfortunately, some men present with permanently damaged renal function. The incidence of this complication is very low, being less than $0.5 \%$ of men undergoing prostatectomy and less than $5 \%$ of men with chronic retention. However, additional men may present to nephrologists; the underlying outflow obstruction may be missed. This may be of importance if a renal transplant is made into the obstructed lower urinary tract. Urodynamic studies should be performed in men being considered for transplantation in whom obstructive uropathy is a possible cause of the original renal failure.

Sacks and his colleagues recently studied 19 men presenting to nephrologists with irreversible renal failure. ${ }^{12} \mathrm{He}$ found that 5 of 19 men presenting with severe renal failure owing to outflow obstruction had renal impairment at the time of their previous prostatectomy carried out between 2 and 13 years 
before referral; two of them died. It is likely that these men had chronic retention and large residual urines. This finding reinforces the point made above, that after prostatectomy in such patients, renal function and bladder emptying should be checked at the subsequent outpatient visit

The other finding in this recent study, ${ }^{12}$ reflecting the inadequate provision of urological services in the UK, ${ }^{31}$ was that two of the 19 men were on a waiting list for prostatectomy, one of whom died. It is likely that these two men had large residual urines at the time of their original assessment because the time course of this condition is long. ${ }^{32}$ If the waiting list for prostatectomy is long, the urologist must assess bladder emptying, upper tract function and biochemical aspects of renal function.

\section{Identification of men at risk}

Theoretically, irreversible renal failure resulting from outflow obstruction should be preventable if men at risk were identified before renal failure occurs. This ideal is probably not, however, achievable in practice.

There are over 6 million men in the UK aged 45-64 years; ${ }^{33}$ screening would represent an enormous workload and investment of funds. This could be justified only if it were part of regular health screening for well men and included items such as a careful history, rectal examination to detect prostate cancer ${ }^{34}$ and rectal cancer, biochemical testing of urine and faeces and measurement of blood pressure. Whether elderly men at risk would attend such screening is debatable.

Screening by regular symptom questionnaire would entail referral to a urologist of most men with symptoms. It has been pointed out above that men at greatest risk of renal impairment are those with impaired bladder emptying. Unfortunately, no symptom is associated specifically with impaired bladder emptying ${ }^{17,20,35}$ and not all men with large residual urines have a palpable bladder. The solution suggested by Sacks and his colleagues $^{12}$ was to measure serum creatinine. However, as mentioned previously, a raised creatinine is non-specific, non-sensitive, and is a late finding in men with decompensated outflow obstruction.

The only accurate method would be to take a

\section{References}

1. Berry, S.J., Coffey, D.S., Walsh, P.C. \& Ewing. L.L. The development of human benign prostatic hyperplasia with age. J Urol 1984, 132: 474-479.

2. Thomson-Walker, J. The Lettsomian lectures on Enlarged Prostate and Prostatectomy. Trans Med Soc London 1930, 53: 143-220. careful history, measure peak urinary flow rate, perform an ultrasound measurement of residual urine and possibly assess the upper urinary tracts. It will be many years hence before facilities such as these become available either in the hospital or community setting in the United Kingdom, unless a totally different order of funding for health care is made available. It is well known that the UK has one of the lowest investments in health care in Western Europe, expressed as a proportion of its gross national product. Another sorry figure, is that the number of urologists is much lower than in most other Western countries - fewer than a half of urological cases being treated by surgeons who have completed specialized urological training. ${ }^{31}$

\section{Conclusions}

For the time being, then, outflow obstruction should be remembered as a potentially treatable cause of renal impairment in the elderly male, particularly in those with a large residual urine: these men require urgent referral. A plea was made some years ago, ${ }^{36}$ that the elderly man and his general practitioner should be aware that normal ageing does not involve waiting several minutes to pass urine, getting up thrice a night, having the indignity of having to pass water urgently or of being incontinent. Many of these men can be helped and should be offered a urological appointment. Meanwhile, urologists with a long waiting list for prostatectomy should be aware that identification of men at risk is a clear responsibility: these men must not be allowed to languish on a waiting list for lack of effort in their identification.

Theoretically, then, many men could be prevented from developing renal impairment because of outflow obstruction if they were to be identified and treated at an earlier stage. In practice, however, this ideal will not be achieved easily. Some men will only present themselves when renal impairment has occurred, despite increasing symptoms. Any improvement in the situation will require easy access for elderly men to up-to-date and well resourced urological services; it will also entail better informed general practitioners and a better informed public. This end is still a long way off.

3. Mebust, W.K., Holtgrewe, H.L., Cockett, A.T.K. et al. Transurethral prostatectomy: immediate and post-operative complications. J Urol 1989, 141: 243-247. 
4. Roos, N.P., Wennberg, J.E. \& Malenka, D.J. Mortality and reoperation after open and transurethral resection of the prostate for benign hyperplasia. $N$ Engl J Med 1989, 320: 1120-1124.

5. Wennberg, J.E., Roos, N.P., Sola, L., Schori, A. \& Jaffe, R. Use of claims data systems to evaluate health care outcomes. JAMA 1987, 257: 933-966.

6. Roos, N.P. \& Ramsay, E.W. A population-based study of prostatectomy: outcomes associated with differing surgical approaches. J Urol 1987, 137: $1181-1188$.

7. Fowler, F.J., Wennberg, J.E., Timothy, R.P., Barry, M.J. Mulley, A.G. \& Hanley, D. Symptom status and quality of life following prostatectomy. JAMA 1988, 259: 3018-3022.

8. Wennberg, J.E., Mulley, A.G., Hanley, D. et al. An assessment of prostatectomy for benign urinary tract obstruction. JAMA 1988, 259: 3027-3030.

9. Neal, D.E., Ramsden, P.D., Sharples, L. et al. Outcome of elective prostatectomy. Br Med J 1989, 299: 762-767.

10. Editorial. TU or not TU. Lancet 1989, i: 1361-1362.

11. Neal, D.E. Prostatectomy - an open or closed case. Br J Urol 1990 , in press.

12. Sacks, S.H., Aparicio, S.A.J.R., Bevan, A., Oliver, D.O., Will, E.J. \& Davison, A.M. Late renal failure due to prostatic obstruction: a preventable disease. $\mathrm{Br} \mathrm{Med} J$ 1989, 298: $156-159$.

13. Lytton, B., Emery, J.M. \& Harvard, B.M. The incidence of benign prostatic obstruction. J Urol 1968, 99: 639-645.

14. Glynn, R.J., Campion, E.W., Bouchard, G.R. \& Silbert, J.E. The development of benign prostatic hyperplasia among volunteers in the normative aging study. Am J Epidemiol 1985, 121: $78-90$.

15. Sommer, P., Nielsen, K.K., Bauer, T. et al. Voiding patterns in men evaluated by a questionnaire survey. Br J Urol 1990 , 65: $155-160$.

16. Abrams, P.H., Roylance, J. \& Feneley, R.C.L. Excretion urography in the investigation of prostatism. Br J Urol 1976, 48: $681-684$.

17. Neal, D.E., Styles, R.A., Powell, P.H. \& Ramsden, P.D. The relationship between detrusor function and residual urine in men undergoing prostatectomy. Br J Urol 1987, 60: 560-566.

18. Abrams, P.H., Dunn, M. \& George, N. Urodynamic findings in chronic retention of urine and the relevance to results of surgery. Br Med J 1978, 2: 1258-1260.

19. George, N.J.R., O'Reilly, P.H., Barnard, R.J. \& Blacklock, N.J. High pressure chronic retention. $\mathrm{Br}$ Med J 1983, 286: 1780-1783.

20. Styles, R.A., Ramsden, P.D. \& Neal, D.E. Chronic retention of urine. The relationship between upper tract dilatation and bladder pressure. Br J Urol 1986, 58: 647-651.
21. Ball, A.J., Feneley, R.C.L. \& Abrams, P.H. The natural history of untreated 'prostatism'. Br J Urol, 1981, 53: 613-616.

22. Abrams, P.H. Prostatism and prostatectomy: the value of urine flow rate measurement in the preoperative assessment for operation. J Urol 1977, 117: 70-71.

23. Styles, R.A., Neal, D.E., Griffiths, C.J. \& Ramsden, P.D. Long term monitoring of bladder pressure in chronic retention of urine: the relationship between detrusor function and upper tract dilatation. J Urol 1988, 140: 330-334.

24. Webb, R.J., Styles, R.A., Griffiths, C.J., Ramsden, P.D. \& Neal, D.E. Ambulatory monitoring of bladder pressure in patients with low compliance as a result of neurogenic bladder dysfunction. Br J Urol 1989, 64: 150-154.

25. Gosling, J.A., Gilpin, S.A., Dixon, J.S. \& Gilpin, C.J. Decrease in the autonomic innervation of human detrusor muscle in outflow obstruction. $J$ Urol 1986, 136: 501-504.

26. Bratt, C.-G. \& Fall, M. Bladder and upper urinary tract overdistension after silent infravesical obstruction. Neurourol' Urodynam 1985, 4: 203-210.

27. Melchior, J., Valk, W.L., Foret, J.D. \& Mebust, W.K. Transurethral prostatectomy: computerized analysis of 2,223 consecutive cases. J Urol 1974, 112: 634-642.

28. Jones, D.A., George, N.J.R., O'Reilly, P.H. \& Barnard, R.J. The biphasic nature of renal functional, recovery following relief of chronic obstructive uropathy. $B r J$ Urol 1988, 61: $192-197$.

29. Nissenkorn, I., Savion, M. \& Servadio, C. Renal and bladder function recovery after prostatectomy in patients with chronic retention of urine above $1000 \mathrm{ml}$. Eur Urol 1988, 14: 434-436.

30. Webb, R.J., Lawson, A.L. \& Neal, D.E. Clean intermittent self-catheterisation in adults. Br J Urol 1990, 54: 20-23.

31. Yeates, W.K. British urology 1982. Ann R Coll Surg Engl 1983, 65: 194- 197.

32. George, N.J.R., Feneley, R.C.L. \& Roberts, J.B.M. Identification of the poor risk patient with prostatism and detrusor failure. Br J Urol 1986, 58: 290-295.

33. Population density 1986. In Regional Trends, 23. HMSO, London, 1988, pp. 48-49.

34. Thompson, I.M., Maj, M.C. \& Fair, W.R. Screening for carcinoma of the prostate: efficacy of available screening tests. World J Surg 1989, 13: 65-70.

35. Neal, D.E., Styles, R.A., Ng, T., Powell, P.H., Thong, J. \& Ramsden, P.D. The relationship between voiding pressures, symptoms and urodynamic findings in 253 men undergoing prostatectomy. Br J Urol 1987, 60: 554-559.

36. Blandy, J.P. The indications for prostatectomy. Urol Int 1978, 33: $159-170$ 